Corrigenda

\title{
Constancy and characteristics of the anterior cutaneous branch of the first intercostal nerve: Correcting the descriptions in human anatomy texts
}

\author{
Makoto Miyawaki
}

Anatomical Science International (2006) 81, 225-241

There were some typographical errors in Table 1. The corrected version of the table is shown opposite.

In the Figure 1 legend, line 11, 99-7786 should have been shown as 99_7786.

\section{Persistent median artery in the hand: A report with a brief review of the literature}

Yoshihiro Tsuruo, Takashi Ueyama, Takao Ito, Sakiko Nanjo, Hiroaki Gyoubu, Keita Satoh, Yukiko lida and Saori Nakai

Anatomical Science International (2006) 81, 242-252

There were some typographical errors in Table 2. The corrected version of the table is shown below.

Table 2. Eight various types (Types a-h) of the superficial palmar arch summarized according to the literature

\begin{tabular}{|c|c|c|c|c|c|}
\hline Type & $\begin{array}{l}\text { Arteries } \\
\text { (distribution) }\end{array}$ & $\begin{array}{l}\text { Classification by } \\
\text { Adachi (1928) }\end{array}$ & $\begin{array}{l}\text { SPA } \\
\text { formation }\end{array}$ & $\begin{array}{l}\text { Incidence } \\
(\%)\end{array}$ & $\begin{array}{l}\text { References: types shown } \\
\text { in the report }\end{array}$ \\
\hline $\mathrm{a}$ & Only UA (1st to 5th digit) & Ulnar type & Incomplete & $37-48$ & $\begin{array}{l}\text { Adachi (1928): a-f } \\
\text { Al-Turk \& Metcalf (1984): a-e, g }\end{array}$ \\
\hline $\mathrm{b}$ & $\begin{array}{l}\text { RA (1st idw) } \\
\text { UA (2nd idw to 5th digit) }\end{array}$ & Ulnar type & Incomplete & 0.5 & $\begin{array}{l}\text { Coleman \& Anson (1961): a-h } \\
\text { Fazan et al. (2004): a, c-f } \\
\text { Henneberg \& George (1992): e }\end{array}$ \\
\hline c & RA and UA (1st to 5th digit) & Radio-ulnar type & Complete & $32-35$ & $\begin{array}{l}\text { Jaschtschinski (1897): a-f, h } \\
\text { Jelicic et al. (1988): a, c-e }\end{array}$ \\
\hline$d$ & $\begin{array}{l}\text { RA (1st and 2nd idw) } \\
\text { UA (3rd idw to 5th digit) }\end{array}$ & Radio-ulnar type & Incomplete & 11 & $\begin{array}{l}\text { Kodama (2000): a-g } \\
\text { Lippert \& Pabst (1985): a-h } \\
\text { McCormack et al. (1953): c, f }\end{array}$ \\
\hline e & MA and UA (1st to 5th digit) & Mediano-ulnar type & $\begin{array}{l}\text { Partially } \\
\text { complete }\end{array}$ & $3.8-5.4$ & $\begin{array}{l}\text { Olave et al. (1997): d-g } \\
\text { Özkus et al. (1998): a-c, f }\end{array}$ \\
\hline$f$ & $\begin{array}{l}\text { MA (1st and 2nd idw) } \\
\text { UA (3rd idw to 5th digit) }\end{array}$ & Mediano-ulnar type & Incomplete & 4 & $\begin{array}{l}\text { Rodriguez-Niedenführ et al. } \\
\text { (1999): e, f, h } \\
\text { Sañudo et al. (1994): f } \\
\text { Singer (1933): f }\end{array}$ \\
\hline$g$ & $\begin{array}{l}\text { RA, MA and UA } \\
\text { (1st to 5th digit) }\end{array}$ & Radio-mediano-ulnar type & Complete & $0.5-1.2$ & $\begin{array}{l}\text { Valdecasas Huelin et al. (1979): e, g } \\
\text { Wood et al. (1997): e }\end{array}$ \\
\hline $\mathrm{h}$ & $\begin{array}{l}\text { RA (1st idw) } \\
\text { MA (2nd idw) } \\
\text { UA (3rd idw to 5th digit) }\end{array}$ & Radio-mediano-ulnar type & Incomplete & 1 & \\
\hline
\end{tabular}

The patterns of the superficial palmar arch (SPA) were grouped into these eight types according to the branches and anastomoses of the radial (RA), median (MA) and ulnar (UA) arteries in the superficial layer of the palm reported in the literature. Each type is characterized by the component arteries, including the distribution to the digits, and the anastomoses between the arteries in the superficial layer of the palm.

The classification by Adachi (1928), such as the ulnar, radio-ulnar, mediano-ulnar and radio-mediano-ulnar types, and the completeness of the SPA, including complete and incomplete types, are shown with the incidence, which is given as a percentage of the total number of subjects.

idw, interdigital web.

The publishers apologize for these errors. 


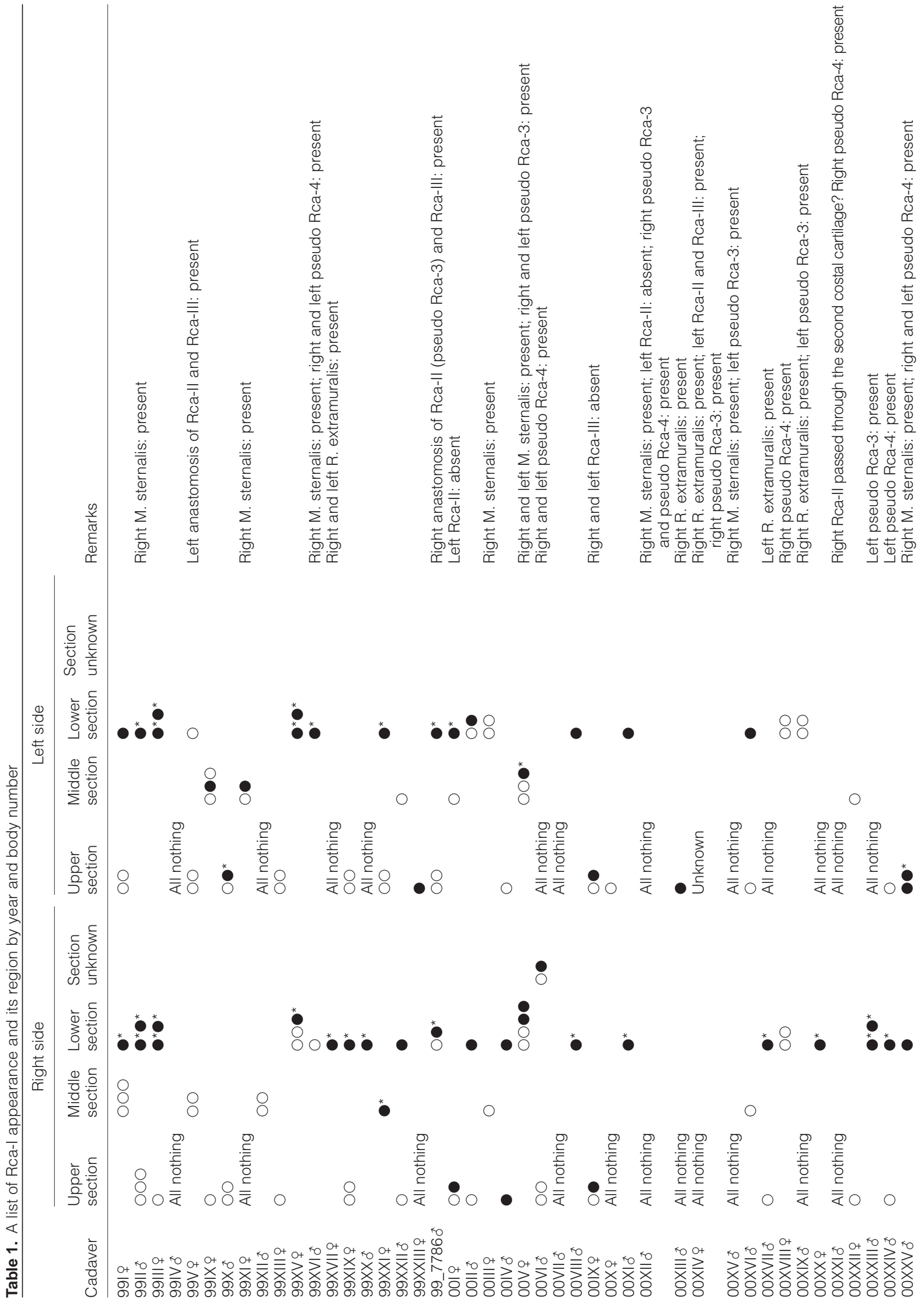




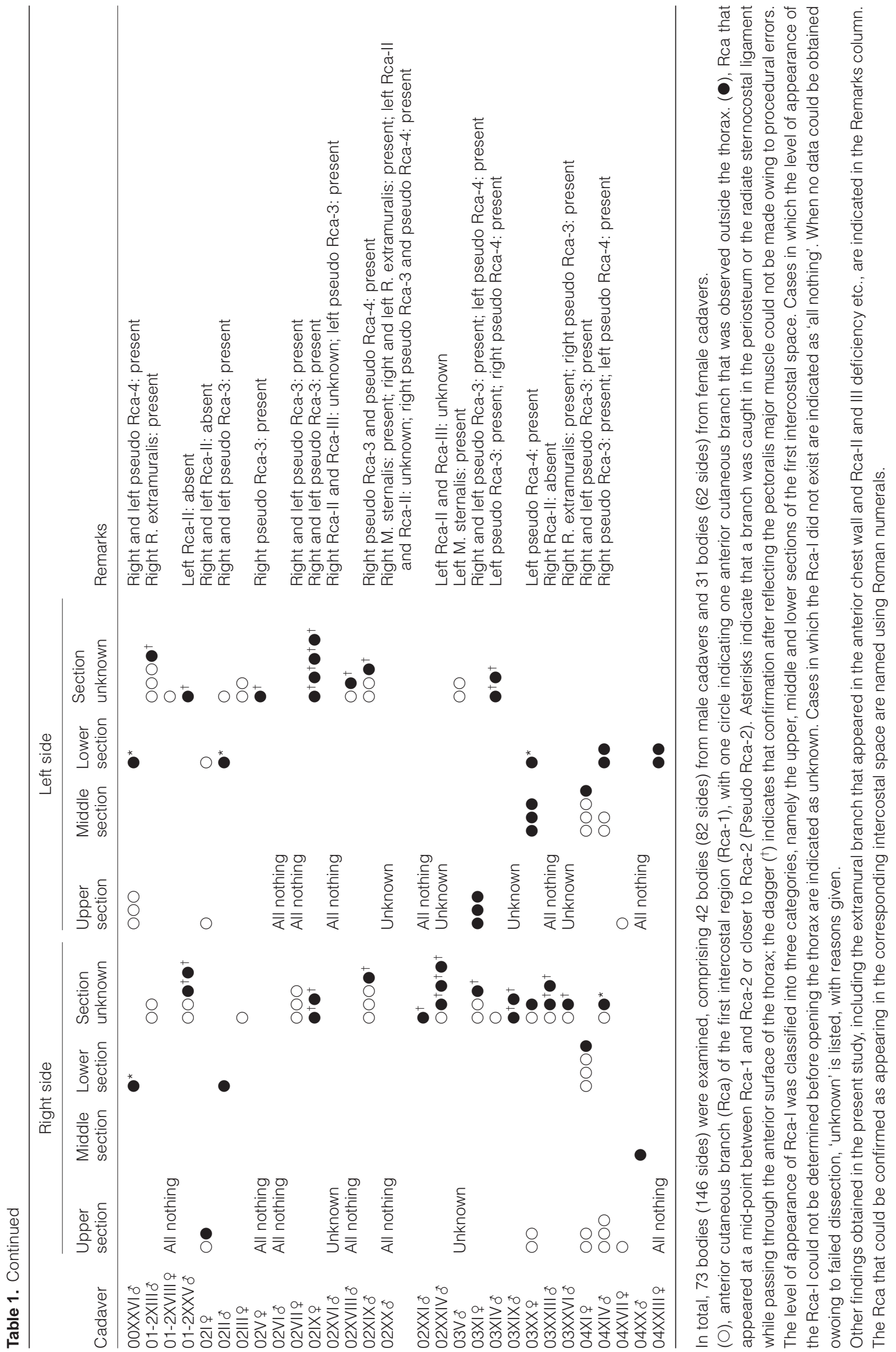

